\title{
Application of non-animal-inspired evolutionary algorithms to reservoir operation: an overview
}

\author{
Mahsa Jahandideh-Tehrani • Omid Bozorg-Haddad • \\ Hugo A. Loáiciga
}

Received: 31 January 2019 / Accepted: 4 June 2019

(C) Springer Nature Switzerland AG 2019

\begin{abstract}
Evolutionary algorithms (EAs) have been widely used to search for optimal strategies for the planning and management of water resources systems, particularly reservoir operation. This study provides a comprehensive diagnostic assessment of state of the art of the non-animal-inspired EA applications to reservoir optimization. This type of EAs does not mimic biologic traits and group strategies of animal (wild) species. A search of pertinent papers was applied to the journal citation reports (JCRs). A bibliometric survey identified 14 pertinent non-animal-inspired EAs, such as the genetic algorithm (GA), simulated annealing (SA), and differential evolution (DE) algorithms, most of which have a number of modified versions. The characteristics of non-animal-inspired EAs and their modified versions were discussed to identify the difference between EAs and how each EA was improved. Additionally, the type of application of non-animal-inspired EAs to different
\end{abstract}

\footnotetext{
M. Jahandideh-Tehrani

Griffith School of Engineering, Griffith University, Gold Coast

Campus, Southport, Queensland, Australia

e-mail: mahsa.jahandideh-tehrani@griffithuni.edu.au

\section{O. Bozorg-Haddad $(\square)$}

Department of Irrigation \& Reclamation Engineering, Faculty of Agricultural Engineering \& Technology, College of Agriculture \& Natural Resources, University of Tehran, Karaj, Tehran, Iran e-mail: OBHaddad@ut.ac.ir
}

\section{H. A. Loáiciga}

Department of Geography, University of California, Santa

Barbara, CA 93016-4060, USA

e-mail: Hugo.Loaiciga@geog.ucsb.edu case studies was investigated, and comparisons were made between the performance of the applied EAs in the studied literature. The survey revealed that the GA is the most frequently applied algorithm, followed by the DE algorithm. Non-animal-inspired EAs are superior to the classical methods of reservoir optimization (e.g., the non-linear programming and dynamic programming) due to faster convergence, diverse solution space, and efficient objective function evaluation. Several non-animal-inspired EAs of recent vintage have been shown to outperform the classic GA, which was the first evolutionary algorithm applied to reservoir operation.

Keywords Bibliography · Metaheuristic algorithm • Dam operation · Optimization · State-of-the-art review

\section{Introduction}

The efficient allocation of water and optimized operation of water system is essential in an environment of scarce water resources (Labadie 2004; Bozorg-Haddad et al. 2013). In this context, the planning and analysis of reservoir systems are key components of integrated water resources management (Bozorg-Haddad et al. 2008; Jahandideh-Tehrani et al. 2014; Ashofteh et al. 2015). Optimization methods are designed to overcome the high dimensional, dynamic, non-linear, and stochastic features of reservoir systems (Labadie 2004). Numerous optimization methods have been developed and applied in reservoir operation (Bozorg-Haddad et al. 2011a, b; Fallah-Mehdipour et al. 2011; Jahandideh- 
Tehrani et al. 2015; Bozorg-Haddad et al. 2017). Reservoir operation optimization methods can be categorized in two main groups: classical methods and evolutionary or metaheuristic algorithms (EAs). Linear programming (LP), dynamic programming (DP), stochastic dynamic programming (SDP), and non-linear programming (NLP) are classical methods, which all suffer from large dimensionality and slow convergence. Therefore, EAs (inspired by biologic phenomena) were developed and have been widely used due their search capacity to find near globally optimal solutions. The genetic algorithm (GA) and particle swarm optimization (PSO) are commonly employed EAs (Bozorg-Haddad et al. 2015; Neboh et al. 2015).

EAs are inspired by evolutionary processes, including the mutation, crossover, selection, and reproduction stages (Nicklow et al. 2010). EAs derive optimal solutions from a population of alternative solutions or designs. EAs identify sets of Pareto optimal solutions applying randomized operators. The randomized operators simulate genetic mutation and recombination to derive new individuals. Individuals' fitness improves the chance of survival through the selection processes framed in terms of fitness functions (Back et al. 2000). On the one hand, EAs are characterized by multi-dimensional, non-linear, non-convex, and discrete problems without having detailed knowledge of the problems' mathematical structure (Fogel 2000) and optimize multi-objective functions (Sarker and Ray 2009). On the other hand, EAs involve heavy computational burden and also require the specification of algorithmic parameters. In spite of these shortcomings, they conclusively outperform classical methods in the solution of complex and multi-objective problems (Blickle 1997).

EAs are inspired by biologic and physical phenomena. Esat and Hall (1994) reported the first application of the GA to optimize reservoir operation with power generation and irrigation functions. Wardlaw and Sharif (1999) assessed the GA's performance with different combinations of parameters, crossover, and mutation probabilities. Teegavarapu and Simonovic (2002) introduced simulated annealing (SA) to reservoir operation problems. Differential evolution (DE) is a stochastic and population-based algorithm, which was proposed by Storn and Price (1995). The immune algorithm (IA), introduced by Forrest et al. (1994), is inspired by the workings of the human immune system. Harmony search (HS) is another example of EA, which is inspired by musical phenomena (Geem et al. 2001).

Reed et al. (2013) reviewed the application of multiobjective EAs in water resources, and Neboh et al. (2015) investigated the application of EAs to hydropower reservoir operation. Reviews of the application of EAs inspired by non-animal phenomena to reservoir operation have not been reported. Countless papers have been published in various outlets dealing with the application of non-animal-inspired EAs to reservoir operation optimization. This work surveys electronic databases, specifically journals published by Elsevier, the American Society of Civil Engineers (ASCE), Springer, John Wiley, the Institution of Civil Engineers (ICE), the International Water Association (IWA), and Taylor and Francis from 1997 to 2018. The present review attempts to identify and highlight the knowledge gaps in the realm of reservoir operation optimization using nonanimal-inspired EAs. Several single and multiobjective non-animal-inspired EAs are compared, providing readers with a comprehensive bibliography which assesses the past performance of non-natureinspired EAs in the field of reservoir operation optimization. The remainder of this paper comprises an outline of the search strategy employed in the survey of the nonanimal-inspired EA-based papers dealing with reservoir operation. This is supplemented with a brief summary of the selected non-animal-inspired EAs, their variants, and their features. Comparisons are also made to evaluate the performance of the non-animal-inspired EAs in solving the reservoir operation problems. The paper ends with a comparison and discussion of the results of present work's survey.

\section{Search strategy}

There are various outlets that publish papers in the area of applications of the non-nature-inspired EAs to the optimization of reservoir operation. Regarding the large number of published papers, the present overview surveyed the journal citation report (JCR) papers published by the previously cited seven main outlets. Therefore, this work's bibliometric search relies on the JCR papers that have appeared in publications by (1) Elsevier, (2) ASCE, (3) Springer, (4) John Wiley, (5) ICE, (6) IWA, and (7) Taylor and Francis from 1997 to 2018. This survey is limited to papers that consider the application 
of non-animal-inspired EAs to reservoir operation. An advanced search for "evolutionary algorithm" was applied to identify relevant publications. This was followed by a search for the word "reservoir" to identify the papers dealing with EA applications to reservoir operation. The search relied on the keywords "evolutionary algorithm," "reservoir," and "optimization."

According to the search results, the top three journals are "Water Resources Management," "Journal of Water Resources Planning and Management," and "Journal of Irrigation and Drainage Engineering" with the largest number of relevant research. The journal Water Resources Management is a leading publisher of nonanimal EAs and reservoir operation optimization. The characteristics and definition of the non-animal-inspired EAs, which have been applied to reservoir operation optimization, are discussed in the following sections. The results of the literature compare the performance and potential of the non-animal-inspired EAs.

\section{Algorithms}

Numerous researchers reported the application of nonanimal-inspired EAs to optimization of reservoir operation and have documented their successful performance in solving reservoir operation problems. Table 1 lists the non-animal-inspired EAs that have been applied to reservoir operation. The GA and the water cycle algorithm (WCA) are the oldest and most recent EAs, respectively.

This survey prospected 135 papers dealing with applications of the non-animal-inspired EAs to reservoir optimization. The GA has been the leading algorithm with major applications in reservoir operation optimization, followed by the DE. Similarly, the largest number of modified versions of the original algorithm belongs to the GA, such as the binary-coded GA and chaos GA. The DE takes second place in the number of modified versions of the original algorithm (i.e., self-adaptive multi-objective DE and fuzzy DE). The next section reviews the definition and features of the non-animalinspired EAs applied to reservoir optimization.

The genetic algorithm

The GA was introduced by Holland (1975). It has been the most commonly applied EA in water resources planning and management. The GA is a population-
Table 1 List of non-animal-based EAs in chronologic order with the oldest listed at the top and the most recent listed at the bottom of the list

\begin{tabular}{|c|c|c|}
\hline Algorithm & Abbreviation & $\begin{array}{l}\text { Year of } \\
\text { appearance }\end{array}$ \\
\hline Genetic algorithm & GA & 1975 \\
\hline Simulated annealing & SA & 1983 \\
\hline Shuffled complex evolution & SCE & 1992 \\
\hline Artificial life algorithm & ALA & 1992 \\
\hline Immune algorithm & IA & 1994 \\
\hline Differential evolution & $\mathrm{DE}$ & 1995 \\
\hline Harmony search & HS & 2001 \\
\hline $\begin{array}{l}\text { S-metric selection evolutionary } \\
\text { multi-objective algorithm }\end{array}$ & SMS-EMOA & 2005 \\
\hline Weed optimization algorithm & WOA & 2006 \\
\hline $\begin{array}{l}\text { The multi-objective evolutionary al- } \\
\text { gorithm based on decomposition }\end{array}$ & MOEA/D & 2007 \\
\hline Imperialist competitive algorithm & ICA & 2007 \\
\hline Biogeography-cased optimization & $\mathrm{BBO}$ & 2008 \\
\hline $\begin{array}{l}\text { Borg multi-objective evolutionary al- } \\
\text { gorithm framework }\end{array}$ & Borg MOEA & 2012 \\
\hline Water cycle algorithm & WCA & 2012 \\
\hline
\end{tabular}

based algorithm. It imitates natural evolution and Darwinian principles of selection, mutation, and recombination (crossover) with various mathematical operators (Affenzeller et al. 2009). Many varieties of the GA have been developed since its introduction. Table 2 lists those varieties in chronological order, with the oldest (i.e., earliest appearance) ones placed at the top of the list.

\section{The binary-coded GA}

The binary-coded GA was introduced by Goldberg (1985). This variety of the GA solves optimization problems using strings (chromosomes), which are comprised of binary bits. These bits encode integers, sets, real numbers, and others in finite length binary strings. Cui and Kuczera (2003) applied the binary-coded GA and the shuffled complex evolution (SCE) method to a water supply system consisting of single reservoir. They discussed that GA is efficient when small population size is selected, while large population size will decrease the GA efficiency; overall, SCE appeared to be more efficient than GA as SCE requires $25 \%$ fewer objective evaluations. However, in the simple water supply system considered in this study, binary-coded GA 
Table 2 Varieties of the GA

\begin{tabular}{|c|c|c|c|}
\hline Algorithm & Abbreviation & $\begin{array}{l}\text { Year of } \\
\text { appearance }\end{array}$ & Reference \\
\hline Binary-coded genetic algorithm & $\begin{array}{l}\text { Binary-coded } \\
\text { GA }\end{array}$ & 1985 & Goldberg \\
\hline Noisy genetic algorithm & NGA & 1988 & $\begin{array}{l}\text { Fitzpatrick and } \\
\text { Grefenstette }\end{array}$ \\
\hline Constrained genetic algorithm & CGA & 1989 & Richardson et al. \\
\hline Real-coded genetic algorithm & RCGA & 1991 & Wright \\
\hline Self-adaptive genetic algorithm & $\begin{array}{l}\text { Self-adaptive } \\
\text { GA }\end{array}$ & 1992 & Bäck \\
\hline Multi-objective genetic algorithm & MOGA & 1995 & Cieniawski et al. \\
\hline Non-dominated sorting genetic algorithm & NSGA-II & 1995 & Srinivas and Deb \\
\hline Hyper cubic distributed genetic algorithm & HDGA & 1997 & Herrera and Lozano \\
\hline Self-learning genetic algorithm & SLGA & 1997 & Han and May \\
\hline Genetic-neuro fuzzy & GNF & 1999 & Seng and Khalid \\
\hline Hybrid genetic algorithm and linear programming & GA-LP & 2001 & Cai et al. \\
\hline Chaos genetic algorithm & Chaos GA & 2002 & Yuan et al. \\
\hline Alternating fitness genetic algorithm & AFGA & 2004 & Zou and Lung \\
\hline Self-organizing map-based multi-objective genetic algorithm & SBMOGA & 2004 & Kubota et al. \\
\hline The non-dominated sorting genetic algorithm with support vector regression & SVR-NSGA-II & 2004 & $\mathrm{Xu}$ et al. \\
\hline Non-dominated sorting genetic algorithm with artificial neural network & NSGA-II-ANN & 2005 & Nain and Deb \\
\hline $\begin{array}{l}\text { A combination of genetic algorithm and discrete differential dynamic } \\
\text { programming }\end{array}$ & GA-DDDP & 2005 & Tospornsampan et al. \\
\hline Genetic algorithm-based support vector machine & GA-SVM & 2005 & Lessmann et al. \\
\hline Epsilon dominance non-dominated sorting genetic algorithm & $\varepsilon$-NSGA-II & 2005 & Kollat and Reed \\
\hline Macro-evolutionary multi-objective genetic algorithm & MMGA & 2007 & Chen et al. \\
\hline GA-based fuzzy proportional derivative & GA-fuzzy PD & 2007 & Bagis and Karaboga \\
\hline Adaptive neural network embedded genetic algorithm & $\begin{array}{l}\text { Adaptive } \\
\text { NN-GA }\end{array}$ & 2009 & Zou et al. \\
\hline Grammatical evolution incorporated with parallel genetic algorithm & GEGA & 2008 & Chen et al. \\
\hline Multi-tier interactive genetic algorithm & MIGA & 2011 & Wang et al. \\
\hline Hybrid incremental dynamic programming and genetic algorithm & Hybrid IDP-GA & 2012 & Li et al. \\
\hline Aggregation hybrid genetic algorithm & AHGA & 2014 & Huang \\
\hline
\end{tabular}

performed better due to its inherent advantages in parallel computing. Jothiprakash and Shanthi (2006) applied single-objective binary-coded GA to the Pechiparai reservoir, India. They extracted a number of rule curves with the binary-coded GA model, which performed better than the actual release due to higher supply of irrigation demand. Moreover, in 2009, the latter authors also compared the binary-coded GA and SDP with respect to the calculation of operating rules for a reservoir in India. Their results indicated that the binary-coded GA reduced the irrigation deficits as the GA model release was equal to the actual demand for almost all months. Therefore, they recommended that the binary-coded GA model was superior over SDP in the selected case study. Kumar and Reddy (2007) compared elitist-mutated particle swarm optimization (EMPSO) with the GA and PSO to obtain optimal operation policies for the multi-purpose reservoir system. Kumar and Reddy's (2007) results indicate that the EMPSO outperformed the PSO and GA in terms of higher quality solutions with fewer functional evaluations. They indicated that the average fitness values are $72.504,80.26$, and 73.389 for the EMPSO, PSO, and GA, respectively. Fallah-Mehdipour et al. (2013) 
compared the performance of the GA, PSO, and shuffled frog leaping algorithm (SFLA) in maximizing the total net benefit of a reservoir irrigation system. Based on their results, the maximum objective function for the GA and PSO was 65.53 and $62.34 \%$, respectively, which were worse than the best value calculated by SFLA. Therefore, it was concluded that SFLA outperforms the GA and PSO. Li et al. (2014) applied seven heuristic algorithms to minimize the amount of water use and maximize the total power generation by the Three Gorges Reservoir, including the binary-coded GA, PSO, SA, dynamically dimensioned search (DDS), dynamic coordinate search using response surface models (DYCORS), and stochastic radial basis function method (SRBF). The latter authors concluded that PSO performed best in optimizing two objectives of the selected case study, which occurred due to increase in diversity of solutions and less dependent on the previous generation compared with other discussed approaches. Zeng et al. (2014) extracted hedging rules for 12 hydropower reservoirs with the binary-coded GA and indicated that the application of the binary-coded GA reduces the power shortage significantly. However, no comparison was performed in the stated research to identify the most efficient algorithm. The artificial bee colony (ABC) algorithm was compared with the GA in a reservoir release optimization problem by Hossain and El-Shafie (2014), who reported that ABC outperformed GA due to lower RMSE values for monthly release curves. According to their results, ABC obtained efficient reliability, resiliency, and vulnerability in release curves. Considering the honeybee mating optimization (HBMO), Bozorg-Haddad et al. (2006, 2009) compared the performance of HBMO with the GA algorithm to optimize reservoir operation using test problems, and the superiority of HBMO over the GA with respect to search capacity, accuracy, and convergence speed was confirmed. Ming et al. (2015) also compared the cuckoo search (CS) algorithm with GA to maximize the energy production of a multi-reservoir system in China. Ming et al.'s (2015) results established that CS improved the energy production by $0.52,0.32$, and $1.64 \%$ in three defined scenarios, respectively (wet year, normal year, and dry year), compared with the GA. Bozorg-Haddad et al. (2014a) have applied the bat algorithm (BA) to optimal operation of a single and multi-reservoir system. The average rating convergence of the BA was compared with the GA. The results indicated that the amount of variation in objective function is insignificant for the
$\mathrm{BA}$, and the coefficient of variation of the BA is almost 16 times less than that of the GA over 10 runs. In another study, the performance of firefly algorithm (FA) was compared with the GA for optimizing irrigation supply and hydropower generation (Garousi-Nejad et al. 2016). According to the comparison, the average values of objective function were closer to the NLP compared with that of the GA, which indicated the superiority of the FA over the GA. Ehteram et al. (2017a) also compared the GA's performance with the shark algorithm. The comparison was made by comparing the performance indexes to optimize the operation of both single and multi-reservoir system. The latter authors reported that the volumetric reliability was $96 \%$ for shark algorithm and $94 \%$ for the GA, and the vulnerability index was $31 \%$ for shark algorithm and $38 \%$ for GA. Hence, they concluded that the shark algorithm outperformed the GA. Ehteram et al. (2017b) compared the monarch butterfly algorithm (MBA) with the GA in the operation optimization of a four-hydroelectric reservoir system. They demonstrated that the MBA improved the accuracy of the GA in power production by $1.16 \%$ in the wet year, $1.28 \%$ in the dry year, and $1.34 \%$ in the normal year. Hossain et al. (2018) applied the $\mathrm{ABC}$ algorithm to develop an optimization water release policy for a reservoir. They also compared the performance of the proposed model with the binary-coded GA. Their results revealed that the binary-coded GA release policy failed to meet the water demand 63 times, while the $\mathrm{ABC}$ release policy failed only four times. Furthermore, the GA performed poor in terms of resiliency, which confirmed the superiority of the ABC over the GA. Parasanchum and Kangrang (2018) applied the binary-coded GA to search the optimal reservoir rule curves under climate change for a reservoir in Thailand. Although this study lacked comparisons, the latter authors concluded the GA model under future climate change conditions indicated a better performance compared with the current rule curves.

Our search of the pertinent literature indicates that the binary-coded GA almost always outperforms classical methods (SDP, DP, and NLP). Although the binary GA is efficient and accurate in extracting reservoir rule curves and hedging rules, new developed algorithms (e.g., CS, BA, ABC, HBMO, and MBA) are more suitable for solving reservoir operation problems by providing higher performance indexes, smaller coefficient of variation, and more efficient convergence. 


\section{The noisy genetic algorithm}

This approach was introduced by Fitzpatrick and Grefenstette (1988). The noisy genetic algorithm (NGA) operates in noisy or uncertain environments. It applies a special kind of fitness function, called effective fitness function, to deal with uncertain environments. Yun et al. (2010) implemented this algorithm for stochastic reservoir operation. They also compared the NGA and the Monte Carlo GA. Their results indicated that the NGA outperformed the Mont Carlo GA in a single stochastic reservoir operation due to shorter computational time and better optimal objective function. The annual cumulative operation loss was US $\$ 206.9384 \times 10^{4}$ and US $\$ 40.4469 \times 10^{4}$ for the Mont Carlo GA and the NGA, respectively, which confirmed the priority of the NGA.

\section{The constrained genetic algorithm}

This algorithm was proposed by Richardson et al. (1989). This algorithm is applied to non-linearly constrained problems. Chang et al. (2010) applied the constrained genetic algorithm (CGA) to the Shih-Men Reservoir, Taiwan, considering human water demand and ecological base flow. They concluded that the CGA approach led to efficient water supply for both noted purposes in terms of generalized shortage index (GSI). Ngoc et al. (2014) optimized the rule curves of s multi-purpose reservoir operation with the CGA. They also demonstrated that the CGA was an effective tool for optimal searching of multi-purpose reservoir operations as the CGA-generated efficient reservoir water releases with small value of GSI (0.33), the smallest value of environmental water shortage $\left(0.11 \mathrm{~m}^{3} / \mathrm{s}\right)$, and the largest water usage $(63.8 \%)$ compared to the current operation of the studied reservoir.

\section{The real-coded genetic algorithm}

Wright (1991) introduced this algorithm. The real-coded genetic algorithm (RCGA) uses real parameter vectors as chromosomes, real parameters as genes, and real numbers as alleles. As a result, solutions are represented in a more straightforward manner than the classic GA. Oliveira and Loucks (1997) applied the RCGA to two hypothetical systems. Oliveira and Loucks (1997) concluded that the RCGA is a practical and robust way of calculating efficient operating policies of multi-reservoir systems. Chang and Chen (1998) compared the efficiency of the RCGA and the binary-coded GA for optimal flood control. Their results indicated that, based on efficiency and precision considerations, the RCGA performed better than the binarycoded GA. Chang and Chen (1998) have also demonstrated that higher mean values of objective function and smaller standard deviation were obtained from the RCGA. Wardlaw and Sharif (1999) applied the RCGA, the gray GA, and the binary-coded GA to a four- and ten-reservoir system to maximize total benefits. Wardlaw and Sharif (1999) concluded that the GA performed three times faster than discrete differential dynamic programming (DDDP) and also the RCGA performed the best among various GAs. Tung et al. and Chen (2003) demonstrated that contrary to methods based on dynamic programming, the RCGA was highly efficient in extracting reservoir operating rule curves. According to results of Tung et al. (2003), the shortage index, days of deficit, and average deficit percentage equaled $7.13,6806$, and $37 \%$, respectively, when operation was optimized by the RCGA, while they equaled $9.81,1962$, and $86 \%$ corresponding to the shortage index, days of deficit, and average deficit percentage, respectively, without using the GA. Chang et al. (2005) and Jian-Xia et al. (2005) reported that the RCGA is more efficient than the binary-coded GA. Chang et al. (2005) reported that in terms of water release deficit, the RCGA obtained a slightly better objective function. Normally, the RCGA is more efficient for reservoir operation optimization and is faster than the binarycoded GA because the increase in the number of variables reduces the efficiency of the binary-coded GA.

The superiority of the HBMO over the RCGA was confirmed by Afshar et al. (2011). They concluded that with the same number of functional evaluations, the improved HBMO enhanced results by more than $8 \%$. Furthermore, Khan and Tingsanchali (2009), Fowe et al. (2015), and Rashid et al. (2015) extracted rule curves with the RCGA. They concluded that the obtained rule curve improved the efficiency of the reservoir operation. However, only the RCGA has been reported in the literature without comparison with other EAs.

The reviewed literature indicates that the RCGA is significantly more efficient than the binary-coded GA and classic methods for solving reservoir operation problems. However, Afshar et al. (2011) have claimed that the HBMO improved the results of the reservoir operation optimization by more than $8 \%$ with the same 
number of function evaluations compared with the RCGA.

\section{The self-adaptive GA}

This algorithm was proposed by Bäck (1992). In this approach, the constraints of the system are developed systematically through the simulation process. Ahmadi Najl et al. (2016) applied the proposed algorithm to extract rule curves of a multi-reservoir system. The latter authors emphasized the benefits of the self-adaptive GA for generating optimal strategies. However, they have not reported performance comparisons with other EAs.

\section{The multi-objective genetic algorithm}

This algorithm was proposed by Cieniawski et al. (1995). The multi-objective genetic algorithm (MOGA) is capable of solving multi-objective problems simultaneously without converting to a weighted objective function. Yang et al. (2007) applied the MOGA to a multi-reservoir system for water supply. They linked the MOGA with constrained differential dynamic programming (CDDP) to generate non-inferior solution sets. Kumphon (2013) applied the MOGA to a multireservoir hydropower system to maximize reservoir releases and storage. According to their results, the modeled release was typically higher than the actual value, and the modeled average storages mainly reached the actual minimum storage value, which presented that MOGA has improved the reservoir operation compared with the actual operation. It is clear that few authors have applied MOGA to reservoir operation; however, this algorithm is suitable for multi-reservoir systems with multiple objectives.

\section{The non-dominated sorting genetic algorithm}

The non-dominated sorting genetic algorithm (NSGA) was introduced by Srinivas and Deb (1995), and the NSGA-II was developed by Deb et al. (2002). The NSGA-II is widely used to solve multi-objective problems. The NSGA-II sorts a population of solutions into different non-dominated solution levels. Operation rules of hydropower reservoirs were calculated with the NSGA-II in many investigations (Kim et al. 2008; Hassaballah et al. 2012; Sreekanth et al. 2012; Ahmadi et al. 2014; Yang et al. 2015; Vonk et al. 2016). Shiau (2009) applied the NSGA-II to a non-hydropower multi- purpose reservoir to obtain a hedging rule. Vonk et al. (2016) compared the NSGA-II and the multi-objective PSO (MOPSO), and their results indicated that both algorithms yielded almost the same Pareto fronts for all assumed scenarios. On the other hand, Baltar and Fontane (2008) indicated that the MOPSO provided more acceptable performance than the NSGA-II and micro GA for solving test functions in terms of generational distance (closeness of the resulting nondominated solutions) and the spacing metric (the distribution of non-dominated solutions). Generational distances were calculated equal to $0.0365,0.0842$, and 0.1508 with the MOPSO, NSGA-II, and micro GA, respectively, and the calculated spacing metrics were $0.1095,0.0985$, and 0.3150 with the MOPSO, NSGAII, and micro GA, respectively. Li et al. (2010) compared the NSGA-II with the multi-objective SFLA. They employed five test problems adapted to a multiobjective reservoir flood operation and compared the mean and variance of the multi-objective SFLA with the NSGA-II for five test problems. The latter authors concluded that solution space diversity and convergence were improved by the multi-objective SFLA compared with the NSGA-II.

Salazar et al. (2016) compared the NSGA-II, epsilon NSGA-II (E-NSGA-II), epsilon multi-objective evolutionary algorithm (E-MOEA), multi-objective evolutionary algorithm based on decomposition (MOEA/D), optimized multi-objective particle swarm optimization (OMOPSO), third evolution step of generalized differential evolution (GDE3), and Borg MOEA. They demonstrated the $\varepsilon$-NSGA-II, E-MOEA, and Borg MOEA have consistently exhibited successful performance. On the other hand, MOEA/D and OMOPSO had poor performance. The GDE3 and NSGA-II revealed poor search convergence. Chen et al. (2016a, b) applied an improved version of the NSGA-II, named the p-NSGAII, which incorporates multiple recombination operators. The Qingshitan hydropower reservoir, China, was selected as the case study. They concluded that the pNSGA-II algorithm improves the solution quality in terms of convergence and diversity compared with the NSGA-II.

Overall, the NSGA-II is an efficient algorithm for solving many multi-objective reservoir problems, particularly operating rule and rule curve extraction problems. However, other multi-objective algorithms such as the epsilon dominance non-dominated sorting genetic algorithm (E-NSGA-II), E-MOEA, Borg MOEA, 
MOPSO, and SFLA may perform better than the NSGA-II due to improved diversity of the solution space and convergence.

\section{The hyper cubic distributed genetic algorithm}

Herrera and Lozano (1997) introduced this algorithm. Current literature review revealed that the stated algorithm was applied by Chen and Chang (2007), who compared the hyper cubic distributed genetic algorithm (HDGA) and the GA. Their results indicated that the HDGA exhibited much better performance than the conventional GA in terms of achieving near optimal objective functions and avoiding local optimal solutions. Two scenarios have been considered based on the absence of a reservoir. The total deficits were $116.8 \times 10^{6} \mathrm{~m}^{3}$ and $71.1 \times 10^{6} \mathrm{~m}^{3}$ for scenarios 1 and 2 , respectively. using HDGA, while the conventional GA obtained the total deficit of $145.9 \times 10^{6} \mathrm{~m}^{3}$ and $85.4 \times 10^{6} \mathrm{~m}^{3}$ for scenarios 1 and 2 , respectively. Hence, the HDGA enhanced the performance of the reservoir optimization efficiently compared with the conventional GA.

\section{The self-learning genetic algorithm}

This algorithm was introduced by Han and May (1997) and modified by Hakimi-Asiabar et al. (2010). The selflearning genetic algorithm (SLGA) is an improved version of the self-organizing map-based multi-objective GA (SBMOGA). The SLGA combines self-organizing map (SOM) and variable neighborhood search (VNS) algorithms and added those two features to the GA, which leads better local search accuracy. HakimiAsiabar et al. (2010) compared the SLGA with the NSGA-II and the SBMOGA and concluded that the SBMOGA outperformed the NSGA-II. However, the efficiency of the SBMOGA was limited by the number of SOM neurons. Hence, the SLGA was applied to overcome this limitation of the SBMOGA by saving SOM's non-dominated solutions in the NSGA-II's nondominated solution set.

\section{The genetic-neuro fuzzy algorithm}

This algorithm was introduced by Seng and Khalid (1999). Pinthong et al. (2009) applied the GNF algorithm to satisfy water demand and prevent flooding in a multi-purpose reservoir operation problem. Input and output data pairs were required in the GNF for training (calibrating) the neuro fuzzy network. The input-output data pairs were also required in the training process to generate the fuzzy rules according to the GA. In other words, the GA was used to search the optimal input combination of a neuro fuzzy system. Their results demonstrated that the proposed algorithm led to higher reliability for the two stated purposes compared with the actual operation.

\section{The hybrid genetic algorithm and linear programming}

Cai et al. (2001) applied the hybrid genetic algorithm and linear programming (GA-LP) to solve two nonlinear models, including (1) a reservoir operation model with non-linear hydropower generation equations and non-linear reservoir topologic equations and (2) a longterm dynamic river basin planning model with numerous non-linear relations. Many studies have applied the GA-LP to multi-reservoir systems (Reis et al. 2005; Reis et al. 2006; Taghian et al. 2013). Reis et al. (2005) demonstrated the superior performance of the GA-LP over stochastic dual dynamic programming (SDDP) considering advantages such as its calculation of operational decisions and its simple implementation. Reis et al. (2006) and Taghian et al. (2013) extracted hedging rules of non-hydropower multi-reservoir system with the GA-LP and reported effective performance.

\section{The chaos genetic algorithm}

Yuan et al. (2002) proposed the chaos GA optimization approach. This algorithm was introduced to address shortcomings of the chaotic optimization method and the GA by combining the chaotic optimization algorithm (COA) and the GA. Cheng et al. (2008) and Jothiprakash and Arunkumar (2013) applied this approach to single hydropower reservoir. Cheng et al. (2008) compared the chaos GA with the simple GA for maximizing power generation. They concluded that the chaos GA outperforms the standard GA in terms of convergence speed and solution accuracy. Moreover, Jothiprakash and Arunkumar (2013) extracted storage rule curves using the chaotic GA and chaotic differential evolution (CDE) algorithms. They concluded the latter two algorithms performed better than the standard GA and $\mathrm{DE}$ algorithms in maximizing power production. Additionally, both the chaotic GA and CDE satisfied the constraints within 400 generations, while simple GA 
and DE could satisfy the constraints within 700 generations. Higher fitness values have also been observed in the results of the chaotic GA and CDE. Arunkumar and Jothiprakash (2013) developed the fully chaotic genetic algorithm (FCGA) to maximize hydropower production of multi-reservoirs in India. The FCGA applies the chaos technique in the mutation and crossover operations except when generating the initial population of solutions of the GA. The latter authors compared their results with the simple GA and DE algorithms and concluded that the FCGA exhibited faster convergence rate.

According to the reviewed literature, the chaotic GA outperforms the standard GA and DE due to faster convergence and higher solution accuracy in reservoir operation optimization.

\section{The alternating fitness genetic algorithm}

Zou and Lung (2004) developed and implemented the alternating fitness genetic algorithm (AFAG) algorithm to overcome the diversity-maintaining problem in the GA solution process. This method alternates functional forms of the GA search for fitness evaluation. Zou and Lung (2004) applied this approach to a single reservoir to control pollution. They concluded that the AFGA outperformed the standard GA because the former algorithm led to higher diversity among the solutions.

\section{The self-organizing map-based multi-objective genetic algorithm}

This approach was introduced by Kubota et al. (2004). The SBMOGA was developed to maintain genetic diversity of a population of solutions. A set of new chromosomes in the next generation of solutions is produced by learning with the SOM. Hakimi-Asiabar et al. (2009) applied this approach to improve the genetic diversity of solutions. The SBMOGA features a grid of neurons that applies the concept of the learning rule with a SOM to improve local and global searches. They compared the performance of the SBMOGA and the NSGA-II by solving a hydropower multi-reservoir system. The convergence of the SBMOGA to the optimal Pareto front was much faster than that of the NSGA-II, and the diversity of the non-dominated solutions of SBMOGA was considerably better than that of the NSGA-II.
The non-dominated sorting genetic algorithm with support vector regression

Xu et al. (2004) combined SVR and NSGA-II. NSGA-II calculates the parameters of SVR and selects historical variables as predictors. Aboutalebi et al. (2015) applied the non-dominated sorting genetic algorithm with support vector regression (SVR-NSGA-II) to optimize monthly operation rules of hydropower generation. Their results demonstrated that this approach performed well in extracting reservoir operation rules in real time with almost $90 \%$ accuracy.

Non-dominated sorting genetic algorithm with artificial neural network

Nain and Deb (2005) integrated NSGA-II with ANN to achieve precise functional evaluations and high diversity of the Pareto front. Shokri et al. (2013) applied this algorithm to address the optimal operation of a reservoir in Iran. They concluded that the hybrid nondominated sorting genetic algorithm with artificial neural network (NSGA-II-ANN) decreased the required time for optimization up to 50 times. Hence, the coupled NSGA-II-ANN led to higher speed of convergence.

\section{Combination of the genetic algorithm and discrete differential dynamic programming}

This algorithm was introduced by Tospornsampan et al. (2005b). They extracted operation policies of a multihydropower reservoir system in Thailand and concluded that the genetic algorithm and discrete differential dynamic programming (GA-DDDP) performed better than the GA in terms of convergence speed.

\section{The genetic algorithm-based support vector machine}

Lessmann et al. (2005) combined the GA and SVM. They formed the solution space combining various kernel parameters and SVM's kernel functions. Su et al. (2013) applied the genetic algorithm-based support vector machine (GA-SVM) to a single reservoir in China to predict monthly reservoir storage. They also compared the GA-SVM with grid search-based SVM (GS-SVM) and particle swarm optimization-support vector machine (PSO-SVM) and claimed that the best performance in calibration and prediction was obtained with the GA-SVM. In another study by Soleimani et al. 
(2016), a data mining model, the LIBSVM model, was coupled with GA to minimize the deviation between the natural temperature regime and the river water temperature downstream of the reservoir using selective withdrawal. It was concluded the that combination of the GA with the LIBSVM reduced optimization process time with the objective of minimizing water temperature in the downstream river.

\section{Epsilon dominance non-dominated sorting genetic algorithm}

Kollat and Reed (2005) combined epsilon dominance archiving with NSGA-II to improve the efficiency, reliability, and ease of use of the NSGA-II. This algorithm is based on the NSGA-II, which classifies solutions through a fast non-dominated sorting approach, and it also preserves solution diversity applying a crowding distance operator. Hurford et al. (2014) implemented this algorithm to extract rule policies for a multireservoir hydropower system. Furthermore, Zhou et al. (2016) applied the E-NSGA-II to a single hydropower reservoir in China. The latter authors proved the forecasting skill of the E-NSGA-II.

\section{The macro-evolutionary multi-objective genetic algorithm}

The macro-evolutionary multi-objective genetic algorithm (MMGA) was inspired by the dynamics of species extinctions over large timescales. It was developed by Chen et al. (2007), who compared rule curves obtained from the MMGA and the NSGA-II. Their results showed that MMGA generates more diverse solutions and closer convergence to the true Pareto front than the NSGA-II.

\section{GA-based fuzzy proportional derivative}

This approach was applied by Bagis and Karaboga (2007) to a single reservoir in Turkey. The GA was applied to improve the main parameters of the fuzzy proportional derivative (fuzzy PD) controller. Their results yielded reservoir operation rules that were accurate and efficient than those of the GAs and led to an improvement in the dynamic response of the system under control.
The adaptive neural network-embedded genetic algorithm

Zou et al. (2009) applied this approach to water quality modeling of a single reservoir in the USA. A set of NN models was developed and incorporated into a GA framework to search near-optimal solutions. They concluded that the adaptive neural network-embedded genetic algorithm (NN-GA) method can identify multiple parameter patterns.

The grammatical evolution incorporated with parallel genetic algorithm

Chen et al. (2008) incorporated the grammatical evolution (GE) into the parallel GA. The grammatical evolution incorporated with parallel genetic algorithm (GEGA) applies the GE to transfer the real-coded string. The GA was combined with the GE to optimize objective functions. Chen et al. (2008) demonstrated that the GEGA is better than traditional linear multiple regression (LMR) given its lower estimation errors.

\section{The multi-tier interactive genetic algorithm}

Wang et al. (2011) proposed the multi-tier interactive genetic algorithm (MIGA), which is suitable for complex systems with high-dimensional variables. This new approach decomposes a complex system into smallscale subsystems. The GA is applied to each subsystem, and multi-tier integration is implemented to the subsystems. Wang et al. (2011) applied this approach to a single hydropower reservoir and compared the calculated rule curves with those obtained with the GA. They reported that the MIGA increased the probability of obtaining an optimal solution. Additionally, the MIGA reduced the computational time by up to $80 \%$.

\section{The hybrid incremental dynamic programming and genetic algorithm}

Li et al. (2012) proposed the hybrid incremental dynamic programming and genetic algorithm (IDP-GA) for long-term operation optimization of large-scale reservoirs. They combined IDP and the GA. The IDP narrows the search space with iterations in highdimensional problems with large feasible domains, and the GA solves highly non-linear, non-convex, problems. Li et al. (2012) applied this method to a hydropower 
multi-reservoir in China. Their results featured that the hybrid IDP-GA outperformed the IDP and the standard GA due to its almost 10 times faster convergence rate.

\section{The aggregation hybrid genetic algorithm}

Huang (2014) applied this approach to the Pepacton Reservoir in the USA. The aggregation hybrid genetic algorithm (AHGA) relies on a weighted sum of scaled simulation errors as the objective function. Huang (2014) showed that their model results matched the observed data well.

Clearly, numerous studies have applied and modified the GA to overcome its shortcomings with specific optimization models. Various combinations of the GA with other EAs or data-driven approaches (e.g., SVM, ANN, and SVR) have improved optimization performance compared with that of the standard GA in terms of convergence speed, accuracy of solutions, and diversity and density of the Pareto fronts of solutions. However, many EAs, including both animal-inspired (e.g., PSO, HBMO, CS, FA, ABC, SFLA, and BA) and nonanimal-inspired (e.g., SA and SCE in the case of large population size) are preferred in reservoir optimization problem due to provision of higher performance indexes, smaller coefficient of variation, and more efficient convergence.

\section{Simulated annealing}

The simulated annealing (SA) was introduced by Kirkpatrick et al. (1983). The SA is a single-point method inspired by homonymous thermodynamical process. Nature finds the minimum state of energy for slowly cooled thermodynamical systems, yet the systems might end in a higher state of energy if it is cooled quickly. The SA was not commonly applied to reservoir optimization. The surrogate-enhanced evolutionary annealing simplex (SEEAS) is the only variety (or modified version) of the SA. Teegavarapu and Simonovic (2002) and Tospornsampan et al. (2005a) applied the SA to a hydropower multi-reservoir system to calculate operation rules. The latter two studies have indicated that the SA is more efficient than the GA due to its faster convergence. Tospornsampan et al. (2005a) demonstrated that the calculated total deficits of defined policy 1 (target storages were set two-thirds active storage curve levels) were 2.255 and $2.282 \%$ for the SA and GA, respectively. The total deficits of policy 2 (target storages were set three-fourths active storage curve levels) were 8.479 and $8.500 \%$ for the SA and GA, respectively. Hence, the superiority of the SA over the GA was reported. Kangrang et al. (2010) applied the SA to two separate hydropower reservoirs in Thailand to obtain rule curves. They concluded that the SA outperformed the GA in determining optimal rule curves of reservoirs. Tsoukalas et al. (2016) proposed the SEEAS by applying it to a hydropower multi-reservoir system in Greece. The SEEAS algorithm combines the strength of surrogate modeling with the evolutionary annealing-simplex method.

In summary, several papers have validated the efficiency of the SA compared with the GA. The surveyed papers indicated that the SA is capable of estimating operating rules and rule curves of various hydropower reservoirs. However, the comparative performances of the GA and SA normally depend on the type of the problem; the SA significantly depends on the choices of parameters as well as fine-tuning of the parameters, while the GA requires high computational costs to obtain accurate solutions, particularly in complex problems.

\section{Shuffled complex evolution}

The SCE was developed by Duan et al. (1992). It is a heuristic global optimization scheme. The SCE samples and partitions a random set of points. Each set of points evolves and improves by using competitive evolution techniques according to the downhill simplex method. A variety of this algorithm was developed at the University of Arizona (SCE-UA) and was reported in three papers to optimize reservoir operation. Valeriano et al. (2010), and Kang and Park (2014) applied this algorithm to single hydropower reservoirs to minimize the difference between the simulated and threshold discharges and the difference between simulated and supply irrigation water, respectively. Yang et al. (2014) introduced the multi-objective complex evolution algorithm (MOCOM) based on the development of the SCEUA named multi-objective shuffled complex evolution with principal component analysis and crowding distance operator (MOSPD) algorithm (Yapo et al. 1998). The latter authors applied the MOSPD to a hydropower multi-reservoir in California and eight test problems. They also compared the MOSPD algorithm with the multi-objective differential evolution (MODE), MOGA, multi-objective simulated annealing (MOSA), MOPSO, 
and MOCOM. Their results demonstrated that MOSPD shows the most consistent performance as well as the best speed and convergence of non-dominated solutions. Overall, reviewed papers suggested that MOSPD outperformed several multi-objective EAs, such as MODE, MOGA, MOSA, MOPSO, and MOCOM.

The artificial life algorithm

The artificial life algorithm (ALA) was introduced by Assad and Packard (1992). This algorithm has been rarely applied to reservoir optimization problems. Hayashi et al. (1996) applied the ALA to solve a nonlinear optimization problem. The ALA is inspired on the interaction of biology and computer sciences (Adami 1998). The ALA was also applied by Dessalegne and Nicklow (2012). The latter paper evaluated the ALA's efficiency in solving a multi-reservoir system with a single objective considering three test problems and demonstrated that the ALA is a global search technique that requires no gradient information, and this algorithm can determine multiple optimal or near optimal solutions.

\section{The immune algorithm}

The immune algorithm (IA) was introduced by Forrest et al. (1994). This algorithm imitates the body's immune system's actions in its approach to solving optimization problems. Lou et al. (2015) applied a multi-objective variety of the IA, called multi-objective algorithm with preference-based selection (MOIA-PS). The MOIA-PS calculates a set of preferred Pareto-optimal solutions rather than a good approximation to the Pareto front. Lou et al. (2015) also compared the MOIA-PS with the NSGA-II and the multi-objective immune algorithm with non-dominated neighbor-based selection (NNIA) for four typical floods at a reservoir. They concluded that the MOIA-PS achieved more non-dominated solutions that were scattered in the preferred area of the Pareto front and successfully reduced the flood peak to no more than $14,000 \mathrm{~m}^{3} / \mathrm{s}$. In another study, Qi et al. (2016) developed a variety of the IA inspired by the memetic algorithm, named multi-objective immune algorithm 2 (M-NNIA2), and solved seven test problems. They made a comparison between the M-NNIA2, NNIA2, NSGA-II, NNIA, and MOEA/D and reported that M-NNIA2 achieved a representative set of best tradeoff scheduling plans, and M-NNIA2 converged to the objective function after 2000 fitness evaluations when the other algorithms had not converged yet.

The surveyed papers suggested that multi-objective IA is capable of solving multi-objective reservoir problems. Although multi-objective IA outperforms some multi-objective algorithms (e.g., NSGA-II, MOEA/D), it has been rarely applied to reservoir optimization. Hence, it is suggested to use this algorithm in optimizing complex reservoir operation problems.

The differential evolution algorithm

The differential evolution (DE) algorithm was introduced by Storn and Price (1995). The DE is a stochastic and a population-based algorithm that applies a parallel search method. The DE has fast convergence and adaptive parameter setting. Guedes et al. (2015) applied the standard DE algorithm to a single hydropower reservoir (in Brazil) to minimize thermal generation and to maximize the future water value. Varieties of the DE are listed in Table 3. The varieties were applied in reservoir optimization papers as recounted in the next sections.

\section{Multi-objective differential evolution}

The MODE was proposed by Xue et al. (2003). They developed the DE for multi-objective optimization problems by proposing a Pareto-based approach to apply the differential vectors. Reddy and Kumar (2007) applied the MODE to single hydropower reservoir using five test problems and compared the MODE with the NSGA-II. The average spacing metric was calculated by 0.425.15 and 124.81 for the MODE and NSGA-II, respectively. Therefore, it was reported that the MODE obtained better Pareto optimal solutions than the NSGA-II. The MODE was applied in two papers (Reddy and Kumar 2008; Schardong et al. 2013) dealing with non-hydropower reservoirs. Schardong et al. 2013 compared the MODE with the NSGA-II considering three test functions and reported that the MODE outperformed the NSGA-II in terms of convergence and coverage of the true Pareto front. Qin et al. (2010) applied multi-objective cultured differential evolution (MOCDE) to a multi-reservoir hydropower system with six test functions. The MOCDE implements cultural algorithms as its framework and the DE to its space of solution populations. Qin et al.'s (2010) results indicated that the MOCDE has uniform coverage and convergence to the true Pareto front. The surveyed papers 
reported that the MODE outperforms the NSGA-II in solving multi-objective reservoir optimization problems.

\section{Self-adaptive multi-objective differential evolution}

This algorithm was introduced by Qin and Suganthan (2005). The self-adaptive multi-objective differential evolution (SMODE) applies a learning strategy and sets parameters in a self-adaptive and gradual manner guided by the learning experience. Schardong et al. (2015) applied the SMODE to a multi-reservoir system in Brazil considering three test functions (ZDT1, KITA, and Kursawe). They compared the SMODE with the NSGA-II and SMODE integrated with out-of-kilter method (SMODE + OFK). The calculated generational distance (GD) was $0.00211,0.00556$, and 0.00179 for SMODE, NSGA-II, and SMODE + OFK, respectively. Furthermore, the spacing metric (SP) was calculated by 0.0641, 0.0614, and 0.0799 for the MODE, NSGA-II, and SMODE + OFK, respectively. Hence, it was concluded the SMODE + OFK outperformed the SMODE and NSGA-II in terms of convergence and accuracy of calculating the true Pareto front.

\section{Fuzzy differential evolution}

Vucetic (2012) proposed the fuzzy differential evolution (FDE). Initialization and mutation procedures are improved by applying fuzzy and stochastic theory in the FDE algorithm. Vucetic and Simonovic (2013) implemented the FDE to the Wildwood hydropower reservoir in Canada. They concluded that the FDE performed better than the standard DE in terms of convergence speed to near optimal solutions.

\section{Harmony search}

The harmony search (HS) was proposed by Geem et al. (2001), who applied it to solve optimization problems. The HS is a population-based metaheuristic algorithm which is inspired by musical phenomena that searches for the most harmonious state. HS was employed as a reservoir optimization method in two studies (Dariane and Karami 2014; Bashiri-Atrabi et al. 2015). The latter authors compared the HS with the HBMO, and they concluded that the HS showed promising results in terms of its convergence speed.
The S-metric selection evolutionary multi-objective algorithm

This algorithm was developed by Emmerich et al. (2005). This approach introduced a selection method based on hyper-volume calculations. Only one paper has applied this algorithm to a non-hydropower, multireservoir, system. Stagge and Moglen (2014) applied the S-metric selection evolutionary multi-objective algorithm (SMS-EMOA) to five reservoirs in the Washington metropolitan area to obtain operating rule modifications. The latter authors demonstrated the efficiency of this algorithm for the purpose of improving system performance.

The weed optimization algorithm

Mehrabian and Lucasc (2006) developed the weed optimization algorithm (WOA). The WOA is a numerical stochastic optimization algorithm inspired by weed colonizing strategies. Asgari et al. (2015) published a paper based on the application of the WOA to a hydropower reservoir optimization. The latter authors compared the HBMO with the GA, LP, and NLP. Moreover, two benchmark functions were applied to validate the efficiency of the WOA. The results by Asgari et al. (2015) determined that the best value of the (minimization) objective function was 0.225 for the GA and 0.1624 for the WOA. Additionally, the WOA obtained smaller standard deviation and coefficient of variation compared with the GA. Asgari et al. (2015) concluded that the WOA had fast convergence to solutions, which were near the global optimal solutions in reservoir optimization problems.

The multi-objective evolutionary algorithm based on decomposition

The multi-objective evolutionary algorithm based on decomposition (MOEA/D) was developed by Zhang and Li (2007). This algorithm decomposes a multiobjective optimization problem into scalar subproblems and optimizes them simultaneously. Two papers applied this algorithm to optimize single reservoir with multiple objectives (Ma et al. 2015; Qi et al. 2016). Eight test problems were used, and a comparison between the MOEA/D and other EAs was made in both papers. Ma et al. (2015) compared the MOEA/D with the light beam search NSGA-II (LBS-NSGA-II) and 
Table 3 Varieties of DE

\begin{tabular}{llll}
\hline Algorithm & Abbreviation & Year of appearance & Reference \\
\hline Multi-objective differential evolution & MODE & 2003 & Xue et al. \\
Self-adaptive multi-objective differential evolution & SMODE & 2005 & Qin and Suganthan \\
Fuzzy differential evolution & FDE & 2012 & Vucetic \\
\hline
\end{tabular}

reported that the MOEA/D performs better than LBSNSGA-II in terms of uniformity and convergence. Similarly, Qi et al. (2016) compared the self-adaptive MOEA/D (SaMOEA/D), MOEA/D, ensemble of different neighborhood size (ENS-MOEA/D), MOEA/DFRRMAB (fitness-rate-rank-based multi-armed bandit in MOEA/D), and indicator-based evolutionary algorithm (IBEA). They indicated that the SaMOEA/D outperforms or performs similarly to the other algorithms and stated that the SaMOEA/D performs better in largescale multi-objective optimization problems.

The imperialist competitive algorithm

Atashpaz-Gargari and Lucas (2007) introduced the imperialist competitive algorithm (ICA). The ICA is inspired by the hypothetical competition between imperialist countries in their quest to control and improve the quantity and quality of their colonies. Two papers were published reporting applications of the ICA to reservoir optimization (Afshar et al. 2014; Hosseini-Moghari et al. 2015). Afshar et al. (2014) compared the ICA and the ant colony optimization (ACO) approach in a singleobjective hydropower reservoir and reported that the ICA exhibited fast convergence to near-optimal solutions to linear operating rule curves, and it slightly outperformed ACO in their case study. Hosseini-Moghari et al. (2015) compared the performance of the ICA, COA, GA, and NLP with a single-objective hydropower reservoir using benchmark problems. The latter authors concluded the COA had the best performance in terms of convergence rate and approaching the global optimum. Thus, it appears that the ICA is not always superior to the other EAs since COA performed better than ICA in the cited paper by Hosseini-Moghari et al. (2015).

Biogeography-based optimization (BBO): is this truly non-animal?

The biogeography-based optimization (BBO) was introduced by Simon (2008). This algorithm is inspired by the geographical distribution of living organisms, which is affected by species migration between habitats, their appearance, adaptation, evolution, and extinction. BozorgHaddad et al. (2015) applied the BBO for single-reservoir and multi-reservoir system optimization in 2015. Three test problems and a benchmark function were employed to compare the performance of the BBO and GA. They have indicated that the $\mathrm{BBO}$ outperforms the GA in terms of minimization of the benchmark functions as the BBO converged $99.94 \%$ of the optimal solution, while the GA converged to $97.46 \%$ of the optimal solution.

The Borg multi-optimization evolutionary algorithm framework

The Borg multi-optimization evolutionary algorithm framework (Borg MOEA) is an open-source evolutionary computational library developed by Hadka and Reed (2012). It consists of six separate search operators which incorporate many features of other MOEAs in order to improve complex solution spaces in multi-objective problems (Smith et al. 2015). Three papers applied the Borg MOEA (Giuliani et al. 2014; Giuliani et al. 2015; and Smith et al. 2015). Giuliani et al. (2014, 2015) applied Borg MOEA to single hydropower reservoir with multiple purposes to derive operation policies. Giuliani et al. (2014) introduced a variety of the Borg MOEA to obtain operating policies that are adaptive to hydroclimatic uncertainties. Next, they combined the optimal policies with visual analytics to propose a decision analytic framework. Smith et al. (2015) combined a water supply model with the Borg MOEA for solving a seven-objective problem with the purpose of multiple reservoir balance. Smith et al. (2015) concluded that the proposed coupled model improves management of existing water infrastructure.

The water cycle algorithm

The water cycle algorithm (WCA) was introduced by Eskandar et al. (2012). This algorithm is based on the 
water cycle and the manner in which rivers flow to lakes and seas. Bozorg-Haddad et al. (2014b) applied the WCA to hydropower single reservoir and multireservoir systems in Iran. Three test problems and one benchmark function were employed, and the results were compared with those of the GA. Based on the compassion, the WCA generated optimum close to 97\% of the global optimum, whereas the GA converged to $79 \%$ of the global optimum. The average calculated objective functions of the WCA were closer to the global optimal solution compared with that of the GA. The latter authors reported the WCA is superior to the GA in terms of convergence to near-optimal solutions, faster convergence rate, and higher reliability.

\section{Conclusion}

This survey established that non-animal-inspired EAs have gained popularity in solving reservoir optimization problems and have outperformed classical methods, such as LP and NLP. This paper's search strategy was limited to electronic database of JCR papers of seven publishers: (1) Elsevier, (2) ASCE, (3) Springer, (4) John Wiley, (5) ICE, (6) IWA, and (7) Taylor and Francis, from 1997 to 2018. Among the publishers, Springer has the largest number of papers in the field of non-animal-inspired EAs and reservoir optimization. The top three journals with the highest percentage of non-animal-inspired EA-reservoir optimization papers are (1) "Water Resources Management," (2) the "Journal of Water Resources Planning and Management," and (3) the "Journal of Irrigation and Drainage Engineering." Additionally, 14 non-animal-inspired EAs were identified in the surveyed papers, and specific analysis of each nonanimal-inspired EA was conducted. The characteristics and definition of the non-animal-inspired EAs have also been discussed in order to help researchers with the proper selection of an EA in their case study. It was found that the non-animal-inspired EAs have been widely used in optimizing reservoir operation which involved hydropower, flood control, water distribution system, drinking water supply, irrigation supply, ecological base flow, rule curve extraction, and inflow forecasting. From our review of non-animal-inspired EAs, it is concluded the GA had the largest numbers of applications and modified versions in the studied literature. This survey concludes that constrained variants of the non-animal-inspired EAs outperform the unconstrained and classic optimization algorithms. Regarding the performance of the GA and SA, it is concluded that the SA's performance relies on the choice of parameters and fine-tuning parameters and the GA requires high computation costs and relatively small population size to obtain accurate solutions. However, the SA is more efficient for solving hydropower reservoir optimization problems and converges faster than the GA. The GA is one of the oldest and efficient evolutionary algorithms, yet this review revealed that in terms of convergence, the CS, ABC, HBMO, BA, FA, HDGA, AFGA, chaotic GA, IDP-GA, GA-DDDP, BBO, and WCA perform better than the conventional GA. Concerning multiobjective optimization problems, it is concluded that MODE, SMODE, MMGA, Borg MOEA, E-NSGA-II, SBMOGA, and NSGA-II-ANN have shown superior performance relative to the classic NSGA-II. The stated conclusion is drawn from a survey of applications to reservoir optimization problems, including single, multi-, hydropower, and non-hydropower reservoir systems.

This paper attempts to highlight the role of nonanimal-inspired EAs in water resources systems, concerning non-animal-inspired EA application to reservoir operation optimization. The identification of the research gaps and development of non-animal-inspired EAs applications to reservoir optimization problems constitutes the main purpose of the present study. Surveyed applications of non-animal-inspired EAs revealed limited consideration of climate change impacts on the operation of reservoirs. These findings are presented as an incentive to encourage the evaluation of climate change impacts on reservoir optimization applying diverse EAs. Additionally, more studies are required to evaluate the efficiency of the existing algorithms on solving reservoir operation problems to identify improved solutions. It is remarked that the current study relied on papers published by the JCR journals. Future surveys including non-JCR publications might yield other helpful insights on the capacities of EAs.

Funding information The study is financially supported by Iran's National Science Foundation (INSF).

\section{Compliance with ethical standards}

Conflict of interest The authors declare that they have no conflict of interest. 


\section{References}

Aboutalebi, M., Bozorg-Haddad, O., \& Loáiciga, H. A. (2015). Optimal monthly reservoir operation rules for hydropower generation derived with SVR-NSGA-II. Journal of Water Resources Planning and Management, 141(11), 04015029. https://doi.org/10.1061/(ASCE)WR.1943-5452.0000553.

Adami, C. (1998). Introduction to artificial life. New York: Springer-Verlag.

Affenzeller, M., Winkler, S., Wagner, S., and Beham, A. (2018). Genetic algorithms and genetic programming: Modern concepts and practical applications. Chapman and Hall/CRC.

Afshar, A., Shafii, M., \& Bozorg-Haddad, O. (2011). Optimizing multi-reservoir operation rules: an improved HBMO approach. Journal of Hydroinformatics, 13(1), 121-139.

Afshar, A., EmamiSkardi, M. J., \& Masoumi, F. (2014). Optimizing water supply and hydropower reservoir operation rule curves: an imperialist competitive algorithm approach. Engineering Optimization, 47(9), 1208-1225.

Ahmadi Najl, A., Haghighi, A., \& Vali Samani, H. (2016). Simultaneous optimization of operating rules and rule curves for multi reservoir systems using a self-adaptive simulationGA model. Journal of Water Resources Planning and Management, 142, 04016041. https://doi.org/10.1061 /(ASCE)WR.1943-5452.0000688.

Ahmadi, M., Bozorg-Haddad, O., \& Mariño, M. A. (2014). Extraction of flexible multi-objective real-time reservoir operation rules. Water Resources Management, 28(1), 131-147.

Arunkumar, R., \& Jothiprakash, V. (2013). Chaotic evolutionary algorithms for multi-reservoir optimization. Water Resources Management, 27(15), 5207-5222.

Asgari, H., Bozorg-Haddad, O., Pazoki, M., \& Loáiciga, H. A. (2015). Weed optimization algorithm for optimal reservoir operation. Journal of Irrigation and Drainage Engineering, 142(2), 04015055. https://doi.org/10.1061/(ASCE)IR.19434774.0000963.

Ashofteh, P. S., Bozorg-Haddad, O., \& Loáiciga, H. A. (2015). Evaluation of climate-change impacts on multiobjective reservoir operation with multiobjective genetic programming. Journal of Water Resources Planning and Management, 141(11), 04015030 . https://doi.org/10.1061 /(ASCE)WR.1943-5452.0000540.

Assad, A. M., and Packard, N. H. (1992). Emergent colonization in artificial ecology. Proceedings of the first European Conference on Artificial Life, MIT press, 143-152.

Atashpaz-Gargari, E., and Lucas, C. (2007). Imperialist competitive algorithm: an algorithm for optimization inspired by imperialistic competition, IEEE Congress on Evolutionary Computation, Singapore, 25-28 September, 4661-4667.

Bäck, T. (1992). The interaction of mutation rate, selection, and self-adaptation within a genetic algorithm. In R. Männer \& B. Manderick (Eds.), Proceedings of Parallel Problem Solvingfrom Nature II (pp. 85-94). Berlin: Springer Verlag.

Back, T., Fogel, D., \& Michalewicz, Z. (2000). Handbook of evolutionary computation. Bristol: IOP Publishing Ltd. and Oxford University Press.

Bagis, A., \& Karaboga, D. (2007). Evolutionary algorithm-based fuzzy PD control of spillway gates of dams. Journal of Franklin Institute, 344(8), 1039-1055.
Baltar, A., \& Fontane, D. (2008). Use of multiobjective particle swarm optimization in water resources management. Journal of Water Resources Planning and Management, 134(3), 257265.

Bashiri-Atrabi, H., Qaderi, K., Rheinheimer, D. E., \& Sharifi, E. (2015). Application of harmony search algorithm to reservoir operation optimization. Water Resources Management, 29(15), 5729-5748.

Blickle, T. (1997). Theory of evolutionary algorithms and applications to system synthesis. Zurich: Swiss Federal school of Technology.

Bozorg-Haddad, O., Afshar, A., \& Mariño, M. A. (2006). Honeybees mating optimization (HBMO) algorithm: a new heuristic approach for water resources optimization. Water Resources Management, 20(5), 661-680.

Bozorg-Haddad, O., Adams, B. J., \& Mariño, M. A. (2008). Optimum rehabilitation strategy of water distribution systems using the HBMO algorithm. Journal of Water Supply: Reaserch and Technology. AQUA, 57(5), 337-350.

Bozorg-Haddad, O., Afshar, A., \& Mariño, M. A. (2009). Optimization of non-convex water resource problems by honey-bee mating optimization (HBMO) algorithm. Engineering Computations, 26(3), 267-280.

Bozorg-Haddad, O., Afshar, A., \& Mariño, M. A. (2011a). Multi reservoir optimization in discrete and continuous domains. Water Management, 164(2), 57-72.

Bozorg-Haddad, O., Moradi-Jalal, M., \& Mariño, M. A. (2011b). Design-operation optimization of run-of-river power plants. Proceedings of ICE-Water Management, 164(9), 463-475.

Bozorg-Haddad, O., Jahandideh-Tehrani, M., \& Mariño, M. A. (2013). Discussion of investigating the vulnerability of dryseason water supplies to climate change: a case study of the Gwangdong Reservoir Drought Management System, Korea by Donghoon cha; Sangeun lee; and Heekyung Park. Water Resources Management, 27(7), 1893-1896.

Bozorg-Haddad, O., Karimirad, I., Seifollahi-Aghmiuni, S., \& Loáiciga, H. A. (2014a). Development and application of the bat algorithm for optimizing the operation of reservoir systems. Journal of Water Resources Planning and Management, 141(8), 04014097-04014091.

Bozorg-Haddad, O., Moravej, M., \& Loáiciga, H. A. (2014b). Application of the water cycle algorithm to the optimal operation of reservoir systems. Journal of Irrigation and Drainage Engineering, 141(5), 04014064. https://doi. org/10.1061/(ASCE)IR.1943-4774.0000832.

Bozorg-Haddad, O., Hosseini-Moghari, S. M., \& Loáiciga, H. A. (2015). Biogeography-based optimization algorithm for optimal operation of reservoir systems. Journal of Water Resources Planning and Management, 142(1), 04015034. https://doi.org/10.1061/(ASCE)WR.1943-5452.0000558.

Bozorg-Haddad, O., Azarnivand, O., Hosseini-Moghari, S. M., \& Loáiciga, H. A. (2017). Optimal operation of reservoir systems with the symbiotic organisms search (SOS) algorithm. Journal of Hydroinformatics, 19(4), 507-521. https://doi. org/10.2166/hydro.2017.085.

Cai, X., McKinney, D. C., \& Lasdon, L. S. (2001). Solving nonlinear water management models using a combined genetic algorithm and linear programming approach. Advances in Water Resources, 24(6), 667-676. 
Chang, F. J., \& Chen, L. (1998). Real-coded genetic algorithm for rule-based flood control reservoir management. Water Resources Management, 12(3), 185-198.

Chang, F. J., Chen, L., \& Chang, L. C. (2005). Optimizing the reservoir operating rule curves by genetic algorithms. Hydrological Processes, 19(11), 2277-2289.

Chang, L. C., Chang, F. J., Wang, K. W., \& Dai, S. Y. (2010). Constrained genetic algorithms for optimizing multi-use reservoir operation. Journal of Hydrology, 390(1-2), 66-74.

Chen, L. (2003). Real coded genetic algorithm optimization of long term reservoir operation. Journal of the American Water Resources Association, 39(5), 1157-1165.

Chen, L., \& Chang, F. J. (2007). Applying a real-coded multipopulation genetic algorithm to multi-reservoir operation. Hydrological Processes, 21(5), 688-698.

Chen, L., McPhee, J., \& Yeh, W. W. G. (2007). A diversified multi objective GA for optimizing reservoir rule curves. Advances in Water Resources, 30(5), 1082-1093.

Chen, L., Tan, C. H., Kao, S. J., \& Wang, T. S. (2008). Improvement of remote monitoring on water quality in a subtropical reservoir by incorporating grammatical evolution with parallel genetic algorithms into satellite imagery. Water Research, 42(1-2), 296-306.

Chen, D., Chen, Q., Leon, A. S., \& Li, R. (2016a). A genetic algorithm parallel strategy for optimizing the operation of reservoir with multiple eco-environmental objectives. Water Resources Management, 30(7), 2127-2142.

Chen, S., Shao, D., Li, X., \& lei, C. (2016b). Simulationoptimization modeling of conjunctive operation of reservoirs and ponds for irrigation of multiple crops using an improved artificial bee colony algorithm. Water Resources Management, 30(9), 2887-2905.

Cheng, C. T., Wang, W. C., Xu, D. M., \& Chau, K. W. (2008). Optimizing hydropower reservoir operation using hybrid genetic algorithm and chaos. Water Resources Management, 22(7), 895-909.

Cieniawski, S. E., Eheart, J. W., \& Ranjithan, S. (1995). Using genetic algorithm to solve a multiobjective groundwater monitoring problem. Water Resources Research, 31(2), 399-409.

Cui, L. J., \& Kuczera, G. (2003). Optimizing urban water supply headworks using probabilistic search methods. Journal of Water Resources Planning and Management, 129(5), 380387.

Dariane, A. B., \& Karami, F. (2014). Deriving hedging rules of multi-reservoir system by online evolving neural networks. Water Resources Management, 28(11), 3651-3665.

Deb, K., Pratap, A., Agarwal, A., \& Meyarivan, T. (2002). A fast and elitist multi objective genetic algorithm: NSGA-II. Transactions on Evolutionary Computation, 6(2), 182-197.

Dessalegne, T., \& Nicklow, J. W. (2012). Artificial life algorithm for management of multi-reservoir river systems. Water Resources Management, 26(5), 1125-1141.

Duan, Q., Sorooshian, S., \& Gupta, V. (1992). Effective and efficient global optimization for conceptual rainfall-runoff models. Water Resources Research, 28(4), 1015-1031.

Ehteram, M., Karami, H., Mousavi, S. F., \& El-Shafie, A. (2017a). Optimizing dam and reservoirs operation based model utilizing shark algorithm approach. Knoledge-Based Sytems, 122, $26-38$.
Ehteram, M., Karami, H., Mousavi, S. F., Farzin, S., \& Kisi, O. (2017b). Optimization of energy management and conversion in the multi-reservoir systems based on evolutionary algorithms. Journal of Cleaner Production, 168, 1132-1142.

Emmerich, M., Beume, N., \& Naujoks, B. (2005). An EMO algorithm using the hypervolume measure as selection criterion. Evolutionary Multi-Criterion Optimization, Springer, Berlin, 62-76.

Esat, V., and Hall, M. J. (1994). Water resources system optimization using genetic algorithms, Proceeding of 1 st International Conference on Hydro informatics, Balkema, Rotterdam, Netherlands, 225-231.

Eskandar, H., Sadollah, A., Bahreininejad, A., \& Hamdi, M. (2012). Water cycle algorithm- A novel metaheuristic optimization method for solving constrained engineering optimization problems. Computers and Structures, 110-111, 151166.

Fallah-Mehdipour, E., Bozorg-Haddad, O., \& Mariño, M. A. (2011). MOPSO algorithm and its application in multipurpose multi reservoir operations. Journal of Hydroinformatics, 13(4), 794-811.

Fallah-Mehdipour, E., Bozorg-Haddad, O., \& Mariño, M. A. (2013). Extraction of multi crop planning rules in a reservoir system: application of evolutionary algorithms. Journal of Irrigation and Drainage Engineering, 139(6), 490-498.

Fitzpatrick, J. M., \& Grefenstette, J. J. (1988). Genetic algorithm in noisy environment. Machine Learning, 3(2), 101-120.

Fogel, D. B. (2000). Evolutionary computation: principles and practice for signal processing. Bellingham: SPIE press.

Forrest, S., Perelson, A. S., Allen, L., and Cherukuri, R. (1994). Self-nonself discrimination in a computer. (PDF). Proceedings of the 1994 IEEE Symposium on Research in Security and Privacy. Los Alamitos, CA. pp. 202-212.

Fowe, T., Nouiri, I., Ibrahim, B., Karambiri, H., \& Paturel, J. E. (2015). OPTIWAM: An intelligent tool for optimizing irrigation water management in coupled reservoir-groundwater systems. Water Resources Management, 29(10), 3841-3861.

Garousi-Nejad, I., Bozorg-Haddad, O., \& Loáiciga, H. A. (2016). Application of the firefly algorithm to optimal operation of reservoirs with the purpose of irrigation supply and hydropower production. Journal of Irrigation and Drainage Engineering, 142(10), 04016041-04016041.

Geem, Z. W., Kim, J. H., \& Loganathan, G. V. (2001). A new heuristic optimization algorithm: harmony search. Simulation, 76(2), 60-68.

Giuliani, M., Herman, J. D., Castelletti, A., \& Reed, P. (2014). Many-objective reservoir policy identification and refinement to reduce policy inertia and myopia in water management. Water Resources Research, 50(4), 3355-3377.

Giuliani, M., Castelletti, A., Pianosi, F., Mason, E., \& Reed, P. (2015). Curses, tradeoffs, and scalable management: advancing evolutionary multi objective direct policy search to improve water reservoir operations. Journal of Water Resources Planning and Management, 142(2), 04015050. https://doi. org/10.1061/(ASCE)WR.1943-5452.0000570.

Goldberg, D. E. (1985). Optimal initial population size for binarycoded genetic algorithms, TCGA Report No. 85001, University of Alabama, Tuscaloosa.

Guedes, L. S. M., Vieira, D. A. G., Lisboa, A. C., \& Saldanha, R. R. (2015). A continuous compact model for cascaded hydropower generation and preventive maintenance scheduling. 
International Journal of Electrical Power \& Energy Systems, 73, 702-710.

Hadka, D., \& Reed, P. (2012). Diagnostic assessment of search controls and failure modes in many-objective evolutionary optimization. Evolutionary Computation, 20(3), 423-452.

Hakimi-Asiabar, M., Ghodsypour, S. H., \& Kerachiam, R. (2009). Multi-objective genetic local search algorithm using Kohonen's neural map. Computers and Industrial Engineering, 56(4), 1566-1576.

Hakimi-Asiabar, M., Ghodsypour, S. H., \& Kerachiam, R. (2010). Deriving operating policies for multi-objective reservoir systems: application of self-learning genetic algorithm. Applied Soft Computing, 10(4), 1151-1163.

Han, S. S., \& May, G. S. (1997). Using neural network process models to perform PECVD silicon dioxide recipe synthesis via genetic algorithm. IEEE Transactions on Semiconductor Manufacturing, 10(2), 279-287.

Hassaballah, K., Jonoski, A., Popescu, I., \& Solomatine, D. P. (2012). Model-based optimization of downstream impact during filling of a new reservoir: case study of Mandaya/ Roseires reservoirs on the Blue Nile River. Water Resources Management, 26(2), 273-293.

Hayashi, D., Satoh, T., \& Okita, T. (1996). Distributed optimization by using artificial life. Transactions of the Institute of Electrical Engineers of Japan, 116(5), 584-590.

Herrera, F., and Lozano, M. (1997). Heterogeneous distributed genetic algorithms based on the crossover operator, 2nd IEE/IEEE International Conference on Genetic Algorithms in Engineering Systems: Innovations and Applications, 203208.

Holland, J. H. (1975). Adaptation in natural and artificial systems. Ann Arbor: University of Michigan Press.

Hossain, M. S., \& El-Shafie, A. (2014). Performance analysis of artificial bee colony (ABC) algorithm in optimizing release policy of Aswan High Dam. Neural Computing and Applications, 24(5), 1199-1206.

Hossain, M. S., El-Shafie, A., Mahzabin, M. S., \& Zawawi, M. H. (2018). System performances analysis of reservoir optimization-simulation model in application of artificial bee colony algorithm. Neural Computing and Applications, 30(7), 2101-2112.

Hosseini-Moghari, S. M., Morovati, R., Moghadas, M., \& Araghinejad, S. (2015). Optimum operation of reservoir using two evolutionary algorithms: Imperialist competitive algorithm (ICA) and cuckoo optimization algorithm (COA). Water Resources Management, 29(10), 3749-3769.

Huang, Y. (2014). Multi-objective calibration of a reservoir water quality model in aggregation and non-dominated sorting approaches. Journal of Hydrology, 510, 280-292.

Hurford, A. P., Huskova, I., and Harou, J. J. (2014). Using manyobjective trade-off analysis to help dams promote economic development, protect the poor and enhance ecological health, $38,72-86$.

Jahandideh-Tehrani, M., Bozorg-Haddad, O., \& Mariño, M. A. (2014). Power generation simulation of a hydropower reservoir system using system dynamics: case study of Karoon reservoir system. Journal of Energy Engineering, 140(4), 04014003. https://doi.org/10.1061/(ASCE)EY.19437897.0000179 .

Jahandideh-Tehrani, M., Bozorg-Haddad, O., \& Loáiciga, H. A. (2015). Hydropower reservoir management under climate change: the Karoon reservoir system. Water Resources Management, 29(3), 749-770.

Jian-Xia, C., Qiang, H., \& Yi-min, W. (2005). Genetic algorithms for optimal reservoir dispatching. Water Resources Management, 19(4), 321-331.

Jothiprakash, V., \& Arunkumar, R. (2013). Optimization of hydropower reservoir using evolutionary algorithms coupled with chaos. Water Resources Management, 27(7), 19631979.

Jothiprakash, V., \& Shanthi, G. (2006). Single reservoir operating policies using genetic algorithm. Water Resources Management, 20(6), 917-929.

Kang, M., \& Park, S. (2014). Combined simulation-optimization model for assessing irrigation water supply capacities of reservoirs. Journal of Irrigation and Drainage Engineering, 140(5), 04014005. https://doi.org/10.1061/(ASCE)IR.19434774.0000726.

Kangrang, A., Compliew, S., \& Hormwichian, R. (2010). Optimal reservoir rule curves using simulated annealing. Water Management, 164(1), 27-34.

Khan, N. M., \& Tingsanchali, T. (2009). Optimization and simulation of reservoir operation with sediment evacuation: a case study of the Tarbela Dam, Pakistan. Hydrological Processes, 23(5), 730-747.

Kim, T., Heo, J. H., Bao, D. H., \& Kim, J. H. (2008). Singlereservoir operating rules for a year using multiobjective genetic algorithm. Journal of Hydroinformatics, 10(2), 163-179.

Kirkpatrick, S., Gelatt, J. r., D, C., \& Vecchi, M. P. (1983). Optimization by simulated annealing. Science, 220(4598), 671-680.

Kollat, J. B., and Reed, P. M. (2005) The value of online adaptive search: a performance comparison of NSGA-II, E-NSGAII, and E-MOEA. In: Coello CC, Aguirre AH, Zitzler E, editors. The Third International Conference on Evolutionary MultiCriterion Optimization (EMO 2005). Lecture Notes in Computer Science, Guanajuato, Mexico: Springer Verlag, 3410, 386-98.

Kubota, R., Yamakawa, Y., and Horio, K. (2004). Reproduction strategy based on self-organizing map, for real-coded genetic algorithms, Neural Information Processing-Letters and Reviews 5, November.

Kumar, D. N., \& Reddy, M. J. (2007). Multipurpose reservoir operation using particle swarm optimization. Journal of Water Resources Planning and Management, 133(3), 192201.

Kumphon, B. (2013). Genetic algorithms for multi-objective optimization: application to a multi-reservoir system in the Chi river basin, Thailand. Water Resources Management, 27(12), 4369-4378.

Labadie, J. W. (2004). Optimal operation of multi reservoir systems: state of the art review. Journal of Water Resources Planning and Management, 130(2), 93-111.

Lessmann, S., Stahlbock, R., \& Crone, S. F. (2005). Optimizing hyperparameters of support vector machines by genetic algorithms. In IC-AI, 74-82.

Li, Y., Zhou, J., Zhang, Y., Qin, H., \& Liu, L. (2010). Novel multi objective shuffled frog leaping algorithm with application to reservoir flood control operation. Journal of Water Resources Planning and Management, 136(2), 217-226. 
Li, F. F., Wei, J. H., Fu, X. D., \& Wan, X. U. (2012). An effective approach to long-term optimal operation of large-scale reservoir systems: case study of the three gorges system. Water Resources Management, 26(14), 4073-4090.

Li, F. F., Shoemaker, C. A., Qiu, J., \& Wei, J. H. (2014). Hierarchical multi-reservoir optimization modeling for realworld complexity with application to the Three Gorges system. Environmental Modeling and Software, 69, 319-329.

Lou, J., Chen, C., \& Xie, J. (2015). Multi-objective immune algorithm with preference-based selection for reservoir flood control operation. Water Resources Management, 29(5), 1447-1466.

Ma, X., Liu, F., Qi, Y., Li, L., Jiao, L., Deng, X., Wang, X., Dong, B., Hou, Z., Zhang, Y., \& Wu, J. (2015). MOEA/D with biased weight adjustment inspired by user preference and its application on multi-objective reservoir flood control problem. Soft Computing, 20, 1-25. https://doi.org/10.1007 /s00500-015-1789-z.

Mehrabian, A. R., \& Lucasc, C. (2006). A novel numerical optimization algorithm inspired from weed colonization. Ecological Informatics, 1(4), 355-366.

Ming, B., Chang, J. X., Huang, Q., Wang, Y. M., \& Huang, S. Z. (2015). Optimal operation of multi-reservoir system basedon cuckoo search algorithm. Water Resources Management, 29(15), 5671-5687.

Nain, P. K. S. and Deb, K. (2005). A multi-objective optimization procedure with successive approximate models. Indian Institute of Technology, Kanpur. http://www.iitk.ac. in/kangal/papers/k2005002.pdf. Accessed 21 Sept 2018.

Neboh, A., Adeyemo, J., Enitan, A., \& Olugbara, O. (2015). A review on application of evolutionary algorithms to reservoir operation for hydropower production. International Journal of Environmental, Chemical, Ecological, Geological and Geophysical Engineering, 9(9), 1115-1121.

Ngoc, T. A., Hiramatsu, K., \& Harada, M. (2014). Optimizing the rule curves of multi-use reservoir operation using a genetic algorithm with a penalty strategy. Paddy and Water Environment, 12(1), 125-137.

Nicklow, J., Reed, S., Savic, D., Dessalegne, T., Harrell, L., ChanHilton, A., Karamouz, M., Minsker, B., Ostfeld, A., Singh, A., \& Zechman, E. (2010). State of the art for genetic algorithms and beyond in water resources planning and management. Journal of Water Resources Planning and Management, 136(4), 412-432.

Oliveira, R., \& Loucks, D. P. (1997). Operating rules for multi reservoir systems. Water Resources Research, 33(4), 839852.

Parasanchum, H., \& Kangrang, A. (2018). Optimal reservoir rule curves under climatic and land use changes for Lampao Dam using genetic algorithm. KSCE Journal of Civil Engineering, 22(1), 351-364.

Pinthong, P., Gupta, A. D., Babel, M. S., \& Weesakul, S. (2009). Improved reservoir operation using hybrid genetic algorithm and neuro fuzzy computing. Water Resources Management, 23(4), 697-720.

Qi, Y., Bao, L., Sun, Y., Lou, J., \& Miao, Q. (2016). A memetic multi-objective immune algorithm for reservoir flood control operation. Water Resources Management, 30(9), 2957-2977.

Qin, A. K., and Suganthan, P. N. (2005). Self-adaptive differential evolution algorithm for numerical optimization, IEEE
Congress on Evolutionary Computation (CEC 2005) Edinburgh, Scotland, IEEE Press, Septmber, 1785-1791.

Qin, H., Zhou, J., Lu, Y., Li, Y., \& Zhang, Y. (2010). Multiobjective cultured differential evolution for generating optimal trade-offs in reservoir flood control operation. Water Resources Management, 24(11), 2611-2632.

Rashid, M. U., Shakir, A. S., Khan, N. M., Latif, A., \& Qureshi, M. M. (2015). Optimization of multiple reservoirs operation with consideration to sediment evacuation. Water Resources Management, 29(7), 2429-2450.

Reddy, M. J., \& Kumar, D. N. (2007). Multiobjetcive differential evolution with application to reservoir system optimization. Journal of Computing in Civil Engineering, 21(2), 136-146.

Reddy, M. J., \& Kumar, D. N. (2008). Evolving strategies for crop planning and operation of irrigation reservoir system using multi-objective differential evolution. Irrigation Science, 26(2), 177-190.

Reed, P. M., Hadka, D., Herman, J. D., Kasprzyk, J. R., \& Kollat, J. B. (2013). Evolutionary multi objective optimization in water resources: the past, present, and future. Advances in Water Resources, 51, 438-456.

Reis, L. F. R., Walters, G. A., Savic, D., \& Chaudhry, F. H. (2005). Multi-reservoir operation planning using hybrid genetic algorithm and linear programming (GA-LP): An alternative stochastic approach. Water Resources Management, 19(6), 831-848.

Reis, L. F. R., Bessler, F. T., Walters, G. A., \& Svaic, D. (2006). Water supply reservoir operation by combined genetic algorithm-linear programming (GA-LP) approach. Water Resources Management, 20(2), 227-255.

Richardson, J. T., Palmer, M. R., Liepins, G., and Hilliard, M. (1989). Some guidelines for genetic algorithms with penalty functions. Proceeding of the third ICGA, Morgan Kaufmann, 191-197.

Salazar, J. Z., Reed, P. M., Herman, J. D., Giuliani, M., \& Castelletti, A. (2016). A diagnostic assessment of evolutionary algorithms for multi-objective surface water reservoir control. Advances in Water Resources, 92, 172-185.

Sarker, R., \& Ray, T. (2009). An improved evolutionary algorithm for solving multi-objective crop planning models. Computers and Electronics in Agriculture, 68(2), 191-199.

Schardong, A., Simonovic, S. P., \& Vasan, A. (2013). Multi objective evolutionary approach to optimal reservoir operation. Journal of Computing in Civil Engineering, 27(2), 139147.

Schardong, A., Simonovic, S. P., \& Vasan, A. (2015). Coupled self-adaptive multi objective differential evolution and network flow algorithm approach for optimal reservoir operation. Journal of Water Resources Planning and Management, 141(10), 04015015. https://doi.org/10.1061 /(ASCE)WR.1943-5452.0000525.

Seng, T. L., \& Khalid, M. B. (1999). Tuning of a neuro-fuzzy controller by genetic algorithm. IEEE Transactions on Systems, Man, and Cybernetics-Part B: Cybernetics, 29(2), 226-236.

Shiau, J. (2009). Optimization of reservoir hedging rules using multi objective genetic algorithm. Journal of Water Resources Planning and Management, 135(5), 355-363.

Shokri, A., Bozorg-Haddad, O., \& Mariño, M. A. (2013). Algorithm for increasing the speed of evolutionary 
optimization and its accuracy in multi-objective problems. Water Resources Management, 27(7), 2231-2249.

Simon, D. (2008). Biogeography-based optimization. IEEE Transactions on Evolutionary Computation, 12(6), 702-713.

Smith, R., Kasprzyk, J., \& Zagona, E. (2015). Many-objective analysis to optimize pumping and releases in multireservoir water supply network. Journal of Water Resources Planning and Management, 142(2), 04015049. https://doi.org/10.1061 /(ASCE)WR.1943-5452.0000576.

Soleimani, S., Bozorg-Haddad, O., Motahareh, S., \& Loáiciga, H. A. (2016). Optimal selective withdrawal rules using a coupled data mining model and genetic algorithm. Journal of Water Resources Planning and Management, 142(12), 04016064.

Sreekanth, J., Datta, B., \& Mohapatra, P. K. (2012). Optimal shortterm reservoir operation with integrated long-term goals. Water Resources Management, 26(10), 2833-2850.

Srinivas, N., \& Deb, K. (1995). Multi-objective function optimization using non-dominated sorting genetic algorithms. Evolutionary Computation, 2(3), 221-248.

Stagge, J., \& Moglen, G. (2014). Evolutionary algorithm optimization of a multireservoir system with long lag times. Journal of Hydrologic Engineering, 19(9), 05014011. https://doi. org/10.1061/(ASCE)HE.1943-5584.0000972.

Storn, R. and Price, R. (1995). Differential evolution — a simple efficient adaptive scheme for global optimization over continuous spaces, International Computer Science Institute, ed. T.R.N. TR-95-012, Calif: Berkley.

Su, J., Wang, X., Liang, Y., \& Chen, B. (2013). A GA-based support vector machine model for the prediction of monthly reservoir storage. Journal of Hydrologic Engineering, 19(7), 1430-1437.

Taghian, M., Rosbjerg, D., Haghighi, A., \& Madsen, H. (2013). Optimization of conventional rule curves coupled with hedging rules for reservoir operation. Journal of Water Resources Planning and Management, 140(5), 693-698.

Teegavarapu, R. S. V., \& Simonovic, S. P. (2002). Optimal operation of reservoir systems using simulated annealing. Water Resources Management, 16(5), 401-428.

Tospornsampan, J., Kita, I., Ishii, M., \& Kitamura, Y. (2005a). Optimization of a multiple reservoir system using a simulated annealing - a case study in the Mae Klong system, Thailand. Paddy and Water Environment, 3(3), 137-147.

Tospornsampan, J., Kita, I., Ishii, M., \& Kitamura, Y. (2005b). Optimization of a multiple reservoir system operation using a combination of genetic algorithm and discrete differential dynamic programming: a case study in Mae Klong system, Thailand. Paddy and Water Environment, 3(1), 29-38.

Tsoukalas, I., Kossieris, P., Efstratiadis, A., \& Makropoulos, C. (2016). Surrogate-enhanced evolutionary annealing simplex algorithm for effective and efficient optimization of water resources problems on a budget. Environmental Modeling and Software, 77, 122-142.

Tung, C. P., Hsu, S. Y., Liu, C. M., \& Li, J. S. (2003). Application of the genetic algorithm for optimizing operation rules of the Liyutan reservoir in Taiwan. Journal of the American Water Resources Association, 39(3), 649-657.

Valeriano, O., Koike, T., Yang, K., \& Yang, D. (2010). Optimal dam operation during flood season using a distributed hydrological model and a heuristic algorithm. Journal of Hydrologic Engineering, 15(7), 580-586.
Vonk, E., Xu, Y. P., Booij, M. J., \& Augustijn, D. C. M. (2016). Quantifying the robustness of optimal reservoir operation for the Xinanjiang-Fuchunjiang Reservoir Cascade. Water Science and Technology: Water Supply, 16(4), 79-86. https://doi.org/10.2166/ws.2015.116.

Vucetic, D. (2012). Fuzzy differential evolution algorithm, M.Sc. thesis, The University of Western Ontario, Slobodan Simonovic.

Vucetic, D., \& Simonovic, S. P. (2013). Evaluation and application of fuzzy differential evolution approach for benchmark optimization and reservoir operation problems. Journal of Hydroinformatics, 15(4), 1456-1473.

Wang, K. W., Chang, L. C., \& Chang, F. J. (2011). Multi-tier interactive genetic algorithms for the optimization of longterm reservoir operation. Advances in Water Resources, 34(10), 1343-1351.

Wardlaw, R., \& Sharif, M. (1999). Evaluation of genetic algorithms for optimal reservoir system operation. Journal of Water Resources Planning and Management, 125(1), 25-33.

Wright, A. (1991). Genetic algorithm for real parameter optimization. In G. J. E. Rawlins (Ed.), Foundations of Genetic Algorithm (pp. 205-218). San Mateo: Morgan Kaufmann.

Xu, Y., Yu-bo, J., \& Xue, T. (2004). Parameters selection of SVM based on genetic algorithm. Fushun Liaoning 113001: School of Information Engineering, Liaoning University of Petroleum \& Chemical Technology.

Xue, F., Sanderson, A. C., Graves, R. J. (2003). Pareto-based multi-objective differential evolution, Proceedings of the 2003 Congress on Evolutionary Computation (CEC'2003), Canberra, Australia, IEEE Press 2, 862-869.

Yang, C., Chang, L., Yeh, C., \& Chen, C. (2007). Multiobjective planning of surface water resources by multiobjective genetic algorithm with constrained differential dynamic programming. Journal of Water Resources Planning and Management, 133(6), 499-508.

Yang, T., Gao, X., Sellars, S. L., \& Sorooshian, S. (2014). Improving the multi-objective evolutionary optimization algorithm for hydropower reservoir operations in the California Oroville-Thermalito complex. Environmental Modeling and Software, 69, 262-279.

Yang, G., Guo, S., Li, L., Hong, X., \& Wang, L. (2015). Multiobjective operating rules for Danjiangkou reservoir under climate change. Water Resources Management, 30(3), 1183-1202.

Yapo, P. O., Gupta, H. V., \& Sorooshian, S. (1998). Multiobjective global optimization for hydrologic models. Journal of Hydrology, 204(1-4), 83-97.

Yuan, X., Yuan, Y., \& Zhang, Y. (2002). A hybrid chaotic genetic algorithm for short-term hydro system scheduling. Mathematics and Computers in Simulation, 59(4), 319-327.

Yun, R., Singh, V. P., \& Dong, Z. (2010). Long-term stochastic reservoir operation using a noisy genetic algorithm. Water Resources Management, 24(12), 3159-3172.

Zeng, Y., Wu, X., Cheng, C., \& Wang, Y. (2014). Chanceconstrained optimal hedging rules for cascaded hydropower reservoirs. Journal of Water Resources Planning and Management, 140(7), 04014010. https://doi.org/10.1061 /(ASCE)WR.1943-5452.0000427.

Zhang, Q., \& Li, H. (2007). MOAE/D: a multiobjective evolutionary algorithm based on decomposition. IEEE 
Transactions on Evolutionary Computations, 11(6), 712731.

Zhou, R., Li, Y., Lu, D., Liu, H., \& Zhou, H. (2016). An optimization based sampling approach for multiple metrics uncertainty analysis using generalized likelihood uncertainty estimation. Journal of Hydrology, 540, 274-286.

Zou, R., \& Lung, W. (2004). Robust water quality model calibration using an alternating fitness genetic algorithm. Journal of Water Resources Planning and Management, 130(6), 471479.
Zou, R., Lung, W. S., \& Wu, J. (2009). Multiple-pattern parameter identification and uncertainty analysis approach for water quality modeling. Ecological Modeling, 220(5), 621-629.

Publisher's note Springer Nature remains neutral with regard to jurisdictional claims in published maps and institutional affiliations. 